\title{
Mestizaje, otredad e identidad en educación básica intercultural. Un análisis del racismo en los textos oficiales
}

DOI: https://doi.org/10.32870/dse.v0i13.243

Diego Morales Esquivel*

\section{Reseña}

Gnade, Jill Renée, 2008, "Raza, racismo y educación escolar en México". Tesis de Doctorado en Estudios Latinoamericanos. México: Facultad de Filosofía y Letras, UNAM,

La tesis doctoral Raza, racismo y educación escolar en México que presentó en 2008 Jill Renée Gnade aborda las manifestaciones implícitas y explícitas de racismo institucionalizado en la educación intercultural en México y hasta ahora no ha sido reseñada. La investigación empieza comentando los mecanismos de identidad y de la construcción del otro desde la perspectiva moderna-occidental y termina comentando los mecanismos de identidad y de alteridad desde la visión y la cultura tojolabal. En el transcurso de su lectura logra evidenciar algunas manifestaciones de racismo y de desprecio cultural en los contenidos de los libros de texto gratuitos y en los cuadernos interculturales de educación básica.

Entre lo más destacable de esta sólida investigación encontramos ejemplos de los cuadernos interculturales manejados de una forma bien fundamentada, para analizar lo que ya en la introducción advertía: que la construcción del "otro no nosotros", desde el contexto poscolonial de México, se ha dado a través de la institución educativa. Y que esta construcción ha generado tensiones entre los objetivos y las realidades de la educación, así como en la conformación de la identidad de los niños y niñas indígenas mexicanos.

En la introducción presenta un estado de la cuestión sobre los vínculos racismo-educación, aún sin ser exhaustivo. Lo valioso es que permite un rastreo de los investigadores más destacados. De entre éstos, es el trabajo crítico de la educación indígena de Benjamín Maldonado, Los indios en las aulas (2005), el que mayor peso tiene en la construcción argumental de Gnade. Sin embargo, en el aspecto curricular, la investigación recurre a Jurjo Torres (1991) y a Cameron McCarthy (1994); y en la historia (secreta) del racismo en México, a Beatriz Urías (2007).

1 Licenciado en Historia por la UNAM, investigador en el Instituto de Estudios Educativos y Sindicales de América (IEESA), colaborador de la Red Integra. Correo electrónico: dfme1986@gmail.com 
En el capítulo 1 la autora analiza dos tipos de manifestaciones del racismo que reproducen esta ideología en la educación: las explícitas y las implícitas. Comenta la autora que de estos tipos de racismo, "El primero es directo, abierto e individual, mientras que el segundo es indirecto, estructural y colectivo, de modo que un 'nosotros' opera desde arriba de manera implícita, reproduciendo una construcción negativa y un patrón discriminador de comportamiento con el 'otro no nosotros"' (p. 39). A partir de estas conceptualizaciones, la autora va centrando su mirada en la institución escolar.

Para enfocar las lentes, el capítulo 2 busca responder a esta pregunta: “¿Es posible considerar la ideología del mestizaje como racista?" (p. 52). Partiendo de que es en la Colonia el momento cuando se imponen las bases del racismo, la autora analiza el proceso por el cual el imaginario "todos somos mestizos" arraigó en la población mexicana del siglo XX. Con ello argumenta que el racismo de México es como una víctima que victimiza. Es decir, que así como en el ámbito nacional la población indígena (aunque habría otras poblaciones a considerar) es puesta en los márgenes de la cultura a reproducir, México a su vez es periférico en el contexto de las relaciones de poder internacionales. Así pues, el racismo poscolonial del país está avalado por instituciones de poder económico y político que imponen lógicas occidentales a las demandas interculturales. Lo anterior le permite aseverar al mestizaje como racismo, "Primeramente porque funciona como un mecanismo autoritario que borra la diferencia y la diversidad" (p. 64). Y abunda: "El mestizaje en México funciona como una pantalla que invisibiliza la diversidad cultural y encubre las desigualdades y el racismo" (p. 71).

Sin embargo, y aunque la siguiente crítica no afecta lo planteado por Gnade, es necesario decir que al momento de revisar algunos autores como Vasconcelos o Molina Enríquez, lo errado de sus contextualizaciones hacen ver como un bloque consciente, como un acto deliberado, el proceso de encumbramiento de la ideología del mestizaje. Y es que citar a la raza cósmica (1925) en 1948 o Los grandes problemas nacionales (1909) en 1964 sólo dificulta la comprensión del porqué la hegemonía de la ideología del mestizaje fue tan seductora; es quitarles a obras y autores su horizonte de enunciación, y desenfocar cómo estos pensamientos afectaron medularmente la construcción del Estado posrevolucionario. Además de reducir y encerrar su valor tanto político como literario en las dinámicas e inercias del burocratismo educativo del régimen prí́sta. Continuemos.

En el capítulo 3, Gnade se enfoca en los libros de texto gratuitos generales (para primarias urbanas interculturales y convencionales) con el objetivo explícito de 1. "Desglosar la construcción/representación de los pueblos originarios"; 2. "esclarecer el manejo y la importancia que se le otorga al tema del mestizaje"; y 3. "indagar sobre la presencia o no del reconocimiento y el respeto a la diversidad cultural" (p. 75). Algo muy valioso es que, aunque la autora centra su análisis en los libros, reconoce que éstos no son tan centrales en el proceso de enseñanza-aprendizaje como a veces se les imputa. Para Gnade el libro es un instrumento más en el aula, sin embargo, aun siendo (que no lo es) marginal, los libros de texto gratuito son una oficialidad cuajada, una versión apro- 
bada por el poder. Entonces, desmenuza contenidos en los libros de primero a sexto año. A veces pidiendo explicaciones profundas a textos que son reduccionistas casi por definición. Sin embargo, logra establecer cómo los textos dan cuenta de una visión un tanto negligente sobre los pueblos y la historia indígena. Resalta las coincidencias entre un silenciamiento de la historia indígena y una promoción de lo moderno. Termina el capítulo con una sentencia clara: "El problema del racismo y de la discriminación existente en los contenidos de los libros de texto actuales es palpable. Quizás no sea un racismo intencionado, pero está presente. Es un racismo tácito e implícito del cual hay que leer entre líneas" (p. 109).

El capítulo 4 se centra en los cuadernos La educación intercultural bilingüe de la Dirección General de Educación Indígena. Lo primero que resalta y abona a la argumentación central es que el contenido de estos cuadernos de apoyo es el mismo en y para todas las culturas indígenas. Estos cuadernos se cubren en dos años, por lo que se dirigen a $1^{\circ}$ y $2^{\circ}$, a $3^{\circ}$ y $4^{\circ}$, y a $5^{\circ}$ y $6^{\circ}$ respectivamente. En éstos, afirma la autora, queda claro "cuál es el enfoque y el mensaje que el gobierno quiere mandar directamente a los niños indígenas" (p. 111). Así, el desprecio cultural y el racismo institucional que la autora ha descrito cobra sustancia.

Quien esto escribe piensa que la autora llega a veces a sobredimensionar algunos elementos de su análisis, sin embargo, es innegable que avanza consolidando su argumentación respecto a las muestras de racismo, de desprecio y de desconocimiento del mundo (de los mundos) indígena. En el análisis de esos cuadernos interculturales, el énfasis en la incorporación y el visto bueno al mestizaje están presentes. El desconocimiento del otro queda demostrado en el caso de una institución -la educativa- que en teoría pretende no sólo reconocerlo sino también valorarlo. El fenómeno se torna hostil a los pueblos indígenas cuando la educación intercultural sostiene y reproduce los prejuicios de la sociedad nacional y de la educación convencional que le han negado visibilidad a los pueblos, historias y culturas indígenas.

Con el último capítulo pareciera que la argumentación inicial sobre los dispositivos de identidad y otredad traspasa el espejo, pues la autora cierra la investigación abordando el tema de la identidad, del saber y de la otredad, ya no desde los ojos del Estado como instancia de dominación, sino desde un enclave cultural que ha resistido la dominación occidental y la imposición del castellano. Basándose en Carlos Lenkersdorf, Gnade hace un sucinto análisis de cómo la lengua tojolabal es diametralmente opuesta en la construcción de la identidad y de la otredad al castellano. Más allá de la figura retórica que en conjunto se logra al iniciar con la otredad occidental y cerrar con la otredad tojolabal, pareciera un añadido forzado hablar del comportamiento de la SEP y la DGEI hacia los pueblos indígenas a lo largo del capitulado, para después enfocarse a la construcción de la realidad de uno de estos, en menoscabo de la línea argumentativa de la educación formal. Empero, es ilustrador este capítulo para enfatizar los desfases y los contrastes entre las propuestas y políticas educativas con las realidades a las que se enfrentan. 
Las conclusiones recuperan y resumen los capítulos anteriores. La autora cierra con una demanda clara a reconocer el racismo en México, tanto el abierto como el oculto, "Los últimos cambios en la política educativa serán superficiales mientras no hayan incurrido en la imagen ni en el trato de los 'otros' que pretenden 'educar'. Los problemas que no se reconocen ni se conocen a fondo no se pueden resolver" (pp. 174-175).

\section{Referencias}

Maldonado Alvarado, Benjamín (2002). Los indios en las aulas: dinámica de dominación y resistencia en Oaxaca. México: INAH.

McCarthy, Cameron (1994). Racismo y currículo: la desigualdad social y las teorías y políticas de las diferencias en la investigación contemporánea sobre la enseñanza. Madrid: Morata.

Molina Enríquez, Andrés (1964) (1909). Los grandes problemas nacionales. México: Instituto Nacional de la Juventud Mexicana.

Torres, Jurjo (1991). El currículum oculto. Madrid: Morata.

Urías Horcasitas, Beatriz (2007). Historias secretas del racismo en México (1920-1950). México: Tusquets.

Vasconcelos, José (2008) (1925). La raza cósmica. México: Trillas. 